\title{
UNGKAPAN LISAN BERMAKNA BUDAYA SUATU TINJAUAN ETNOLINGUISTIK
}

\author{
Sjane F. Walangarei \\ Balai Bahasa Manado
}

\begin{abstract}
Abstrak
Era global dan penyesuaian budaya terjadi di berbagai belahan dunia ini. Budaya yang kuat akan menekan budaya yang kecil. Situasi ini menyebabkan kemerosotan nilai-nilai budaya dan yang paling dikuatirkan adalah kemerosotan etika pada generasi sekarang dan dikuatirkan akan berlanjut pada generasi berikutnya.

Menyikapi hal tersebut, mengangkat budaya orang Tondano adalah salah satu upaya menyelamatkan suatu generasi. Upaya tersebut adalah mengangkat ungkapan yang bermakna budaya di masyarakat Tondano dalam percakapan sehari-hari dan digambarkan secara umum dalam bentuk nasihat dan sindiran. Selain itu, Ungkapan tersebut untuk memperingatkan masyarakat bahwa segala sesuatu memiliki aturan dan harus ditaati sebagai kesepakatan bersama. Hal menarik dari pada masyarakat Tondano yaitu ungkapanungkapan tersebut masih digunakan sampai sekarang. Namun sangat disayangkan, masyarakat Tondano tidak menyadari bahwa ungkapan-ungkapan tersebut merupakan bagian dari bahasa yang mampu menegaskan sikap budaya dan perilaku tentang nilainilai, norma, pola pikir, dan cara hidup masyarakat.

Studi tentang ungkapan-ungkapan budaya masyarakat Tondano dilakukan untuk penyelamatan generasi dari kemerosotan etika dan penyelamatan budaya Tondano yang mengandung nilai sosial dan pemikiran-pemikiran yang mendidik.
\end{abstract}

Kata kunci: ungkapan, pola pikir masyarakat Tondano.

\begin{abstract}
Global and cultural mixture exist around the world. Big culture will press small culture. This situation can cause the decadency of cultural values and the most importantly demoralization in this generation can be passed over the next generation.

This research have been done as one of many ways to save a generation. The research discuss cultural expressions are used by Tondanonese in their daily conversation. These expressions, in general, are in the form of advice and insinuation to warn the society that everything has its rule and must be obeyed by them. Those cultural expressions have been used since long time ago until now. But unfortunately, Tondanonese are unaware those expressions which are in the form of language that emphasize cultural attitudes and actions in which social values/norms, mindsets, and life style existed.

The cultural expressions of Tondanonese research have been done to save this generation from the decadency of ethic and to preserve Tondanonese culture which social values and educated thought bounded.
\end{abstract}

Keywords: expression, mindset, Tondanonese 


\section{Pendahuluan}

Bahasa daerah adalah salah satu kekayaan budaya yang dimiliki oleh setiap suku bangsa dan merupakan warisan turun temurun yang tidak ternilai harganya. Menurut Keesing (1992), bahasa mengkodifikasi realitas yang ada dalam suatu masyarakat. Suatu realita dapat disuguhkan secara mutlak kepada masyarakat melalui bahasanya.

Dalam penelitian ini penulis tertarik untuk mengkaji ungkapan-ungkapan yang bermakna budaya yang yang digunakan sehari-hari pada masyarakat Tondano. Ketertarikan ini didasarkan pada keingintahuan penulis akan ungkapan-ungkapan dalam pergaulan sehari-hari yang digunakan orang Minahasa dari zaman dulu sampai sekarang. Selain itu, ungkapan sehari-hari bahasa Tondano wajib diangkat sebagai ilmu pengetahuan mengenai sikap dan perilaku orang Tondano. Selama ini, masyarakat tidak menyadari bahwa yang selalu diungkapkannya adalah warisan budaya nenek moyang yang sangat bernilai. Ungkapan-ungkapan tersebut mengandung nilai-nilai sosial yang tinggi dan pemikiran yang mendasari pola hidup masyarakat Tondano.

Nilai-nilai sosial dan pemikiran yang dimiliki dan yang diwariskan oleh nenek moyang pada generasi berikutnya dapat dijadikan bahan untuk memahami lebih dekat karakter masyarakat Tondano untuk tujuan-tujuan mulia. Seperti, peningkatan taraf hidup baik dari segi ekonomi dan religi tanpa harus mengorbankan cara pandang atau budaya yang berlaku pada masyarakatnya.

Ungkapan masyarakat Tondano sehari-hari, antara lain, adalah kekos kekei, leos tiko 'celana panjang (celana kerja) basah, tenggorokan baik' makna yang terkandung adalah "orang yang bangun pagi dan pergi bekerja sebelum matahari terbit yaitu saat embun pagi masih membasahi rumput dan daun-daun di sepanjang jalan menuju kebun maka orang tersebut pada akhirnya menikmati hasil pekerjaannya. Memulai pekerjaan sebelum matahari terbit adalah pola hidup yang baik dan masih relevan dengan kehidupan sekarang.

Paewen lewo ‘mengidam jahat' adalah ungkapan yang menggambarkan seorang ibu hamil yang mengalami gangguan kesehatan karena kehamilan. Mengidam jahat adalah situasi yang tidak mengenakan bagi seorang ibu hamil dimana dia akan mengalami bebarapa hal, yaitu setiap kali makan dimuntahkan atau ingin makan sesuatu saat makanan ada di depan mata selera makan tiba-tiba hilang. Keadaan ini dapat menyebabkan ibu hamil jatuh sakit sehingga dapat mempengaruhi kesehatan bayi yang ada dalam kandungan. Selain itu, ungkapan ini pun sering juga ditujukan pada seseorang baik laki-laki atau perempuan yang memiliki keinginan yang tidak tertahankan terhadap makanan atau apa saja yang diinginkannya. Ungkapan yang disampaikan adalah berbentuk pernyataan tanumokan tare se paewen lewo 'sudah seperti orang yang mengidam jahat'. Paewen lewo tidak selalu dialami oleh ibu hamil, tetapi namun ini berupa kasus dan akan selalu ada.

Ungkapan yang bermakna budaya digunakan oleh masyarakat Tondano dalam percakapannya sehari-hari. Dalam percakapan tersebut masyarakat tidak sadar bahwa mereka sedang melestarikan dan mewariskan nilai-nilai budaya dan pandangan hidup kepada generasi dan generasi berikutnya dengan media bahasanya.

Berdasarkan latar belakang pemikiran tersebut, masalah dapat dirumuskan sebagai berikut: (1) Apa makna yang terkandung dalam ungkapan budaya pada bahasa Tondano? (2) Bagaimana bentuk pola pikir masayarakat Tondano dalam ungkapan budaya tersebut. Berdasarkan masalah yang ada, maka penelitian ini diadakan dengan tujuan 
untuk: (1) Mengungkapkan makna yang terkandung dalam ungkapan-Ungkapan budaya masyarakat Tondano; (2) Mengetahui pola pikir masyarakat Tondano melalui ungkapanungkapan budaya. Hasil penelitian ini diharapkan dapat bermanfaat sebagai berikut: (1) Acuan untuk memahami pola pikir dan karakter masyarakat Tondano; (2) Untuk mengembangkan kajian linguistik antropologi, dan; (3) Menjadi aset budaya daerah dan budaya nasional.

Penelitian tentang ungkapan budaya sehari-hari masyarakat Tondano belum ditemukan, tetapi penelitian yang berhubungan dengan konsep budaya masyarakat Tondano dapat dilihat melalui karya-karya seperti berikut.

Beberapa penelitian yang memadukan bidang sosiolinguistik dan etnolinguistik yang telah dilakukan; di antaranya penelitian yang berjudul "Pilihan Bahasa dalam Situasi Kedukaan di Daerah Tonsea" oleh Manoppo dan Mawuntu (1990). Dalam penelitian ini dideskripsikan bahasa yang digunakan dalam setiap tahap pada proses kedukaan menurut adat Tonsea. Penelitian ini bertujuan untuk mendeskripsikan penggunaan bahasa pada setiap tahap pada prosesi perkawinan menurut adat Tonsea. Dalam penelitian tersebut dijelaskan bahwa dalam setiap tindakan berkomunikasi terdapat interlokutor, yaitu seorang pengirim (sender), seorang atau beberapa orang penerima (receiver), dan audience. Oleh peneliti yang sama secara etnolinguistik telah dilakukan pula penelitian berjudul "Pilihan Bahasa dalam Situasi Perkawinan di daerah Tonsea (1991).

Spradley (1969) dalam kajian antropologi mengkaji kebudayaan sebagai sistem pengetahuan (kognisi) yang meliputi tingkah laku (behavior), gagasan (ide), dan pengetahuan (knowledge) dari suatu masyarakat. Masinambouw (1998:14) mengatakan bahwa kebudayaan merupakan suatu keseluruhan yang kompleks menyangkut semua yang dapat kita amati pada manusia sebagai makhluk sosial dan dengan sendirinya termasuk bahasa di dalamnya. Bahasa merupakan salah satu komponen kebudayaan. Konsep seperti ini akan memperlihatkan hubungan antara bahasa dengan kebudayaan secara jelas dengan mengambil aspek-aspek yang lebih spesifik lagi misalnya ungkapan-ungkapan budaya suatu masyarakat.

Sapir dan Whorf dalam tulisan Casson (1981) mengatakan bahwa bahasa mempunyai hubungan dengan kebudayaan. Kebudayaan ditentukan oleh bahasa karena bahasa merupakan petunjuk kebudayaan. Seorang tidak dapat memahami bahasa dan menilai kebudayaan tanpa memahami keduanya. Sapir (1957) mengatakan bahwa bahasa sangat bermanfaat tentunya untuk menjadi penuntun dalam mempelajari budaya suatu masyarakat. Bahasa itu lazim dikuasi oleh informan untuk dapat menjelaskan makna budaya melalui jendela bahasa yang dikuasainya. Melalui bahasa mungkin dapat dipahami berbagai register, idiom, ungkapan bahasa sebagai kristal pengalaman tentang peristiwa budaya dalam kehidupan masyarakat sehari-hari.

\section{Metodologi}

Analisis yang akan digunakan dalam penelitian ini adalah analisis etnolinguistik yang terdiri atas analisis komponen dan tema. Menurut Spradley (1969:229), analisis komponen untuk mengamati secara sistematis komponen-komponen makna yang berhubungan dengan simbol budaya. Hal itu berguna untuk menentukan tema budaya, pola pikir, dan pandangan hidup. Dari analisis ini dapat dihasilkan uraian mengenai pola-pola yang mendasari cara berpikir dan tingkah laku masyarakat pendukung suatu kebudayaan. Akan 
tetapi, analisis tema berguna untuk menerapkan tema budaya, nilai-nilai, dan pandangan hidup masyarakat yang bersangkutan.

Penelitian ini bersifat kualitatif dan menggunakan metode etnolingustik. Prosedur penelitian akan menghasilkan data deskriptif dengan mengikuti tahap-tahap dan teknik penelitian sebagai berikut. Lokasi penelitian dilaksanakan di Tondano Minahasa Induk. Pada tahap penelitian lapangan digunakan metode observasi partisipasi. Teknik yang dilakukan adalah merekam, wawancara, dan mencatat. Informan yang diwawancarai adalah orangorang yang berumur 22 tahun sampai dengan 75 tahun. Jumlah informan yang terlibat adalah 5 orang. Data penelitian ini berupa ungkapan yang digunakan sehari-hari. Data yang dikumpulkan dianalisis dari segi maknanya untuk mencapai pola pikir masyarakat Tondano. Metode tersebut untuk menemukan komponen semantik atau gambaran stem menurut Spradley (1969) dan untuk mengetahui atribut (komponen makna) yang dihubungkan dengan simbol-simbol budaya. Analisis ini digunakan untuk menemukan tema budaya, nilainilai sosial, pola pikir sekaligus pandangan hidup masyarakat yang sedang diteliti. Metode analisis dilengkapi dengan analisis lingual masyarakat setempat.

\title{
2. Hasil dan Pembahasan
}

Hasil penelitian yang berupa ungkapan yang mengandung nasihat dan sindiran dari masyarakat Minahasa yang ada di Tondano. Hasilnya sebagai berikut.

\subsection{Pola pikir masyarakat Tondano dalam ungkapan nasihat.}

Ungkapan yang mengandung nasihat pada masyarakat Tondanao pada dasarnya untuk menyadarkan seseorang dari hal tidak baik pada hal yang baik dan benar. Nasehatnasehat tersebut biasanya disampaikan oleh orang tua kepada anak-anaknya atau orang dewasa kepada yang lebih muda.

Contoh ungkapan piipi kekei kekos kekeroaan merupakan nasihat yang menggambarkan bagaimana menjadi orang yang rajin bekerja sejak subuh saat embun pagi masih menempel di dedauan sehingga membuat basah celana panjang yang dipakainya saat pergi ke kebun. Dari makna yang terkandung dalam ungkapan tersebut terbentuklah pola pikir pada masyarakat Tondano bahwa orang rajin bekerja pasti mendapat makan dan banyak rezekinya.

Secara lingual masyarakat Tondano, ungkapan tersebut dapat diterjemahkan sebagai berikut:

\author{
piipi 'basah’ \\ kekei 'celana kerja' \\ kekos 'basah' \\ kekeroan 'tenggorokan'
}

Ungkapan rei pinipitan weren merupakan salah satu ungkapan lain yang digunakan oleh masyarakat Tondano untuk menyatakan seseorang yang rajin dan cepat dalam menyelesaikan pekerjaan. Rajin dan cepat dalam melakukan pekerjaan dihargai sebagai suatu kelebihan yang tidak semua orang memiliki dan orang yang memiliki kelebihan tersebut akan selalu diperhitungkan untuk diberikan tanggung jawab. 
Ungkapan Lisan Bermakna Budaya .....

Secara lingual masyarakat Tondano, ungkapan tersebut dapat diterjemahkan sebagai berikut:

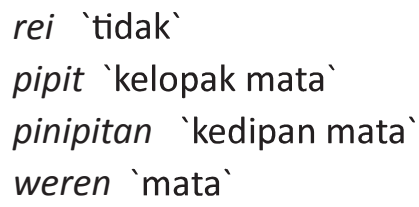

Ungkapan pewali-walian 'bersama-sama' merupakan ungkapan yang mengajarkan bahwa kebersamaan selalu menghasilkan hal yang jauh lebih baik dibandingkan dengan pekerjaan yang dilakukan oleh satu orang saja. Dari ungkapan tersebut membentuk pola pikir masyarakat Tondano untuk selalu mengerjakan pekerjaan berat secara bersama-sama.

Secara lingual masyarakat Tondano, ungkapan tersebut dapat diterjemahkan sebagai berikut:
pinewali-walian
wali 'bersama'
pinewali 'disatukan'
pinewalian 'bersamaan'
pinewalia-walian 'bersama'

Ungkapan : timelewo si owak ko tae mawia artinya Sudah habis semua makanan kamu baru sampai. Ungkapan tersebut mengandung makna bahwa jika mendapat undangan untuk menghadiri sebuah acara atau pesta kita harus datang tepat waktu untuk menghormati orang yang mengundang.

Secara lingual masyarakat Tondano, ungkapan tersebut dapat diterjemahkan sebagai berikut :

Timelewo si owak ko tae mawia 'sudah terbang si burung bangkai, kau baru sampai' telew 'terbang'

timelewo `sudah terbang`

si 'si'

owak ' burung pemakan bangkai’

ko 'kau'

tae 'baru'

wia 'hadir,ada'

mawia 'datang'

Ungkapan pineloanokan embariwis mengandung makna orang yang sangat cepat menghilang. Ungkapan ini selalu ditujukan pada orang yang dicurigai melakukan hal yang tidak benar seperti mencuri. Pola pikir yang terbentuk di masyarakat Tondano bahwa orang yang baru datang atau hendak pergi harus memberi tahu keberadaannya atau keberangkatannya.

Secara lingual masyarakat Tondano, ungkapan tersebut dapat diterjemahkan sebagai berikut :

Pinelooanokan embariwis 'yang dilihat hanya gelembung air'

loo 'lihat’

62 | Ranah, Volume 2, Nomor 1, Juli 2013 
pinelooan 'terlihat'

Pinelooannokan 'tinggal dillihat'

bariwis 'gelembung air'

embariwis 'itu gelembung air` awalan pine dan akhiran an

awalan pine dan akhiran nokan

\subsection{Pola pikir masyarakat Tondano dalam ungkapan sindiran}

Ungkapan-ungkapan yang mengandung sindiran pada masyarakat Tondano dapat disampaikan oleh siapa saja untuk menyadarkan seseorang yang dianggap melakukan hal yang tidak baik. Kata-kata atau kalimat sindiran dalam masayrakat Tondano merupakan salah satu sarana untuk menyadarkan seseorang. Sindiran sebenarnya adalah pilihan kata atau pengandaian agar tidak langsung menyinggung orang yang dimaksud.

Ungkapan ko tanumokan se pengokian merupakan nasihat atau teguran agar jangan terlalu bertingkah aneh dan berdandan tidak pantas. Dalam kehidupan orang Tondano bertingkah laku aneh dan berdandan tidak pantas dianggap tidak sopan.

Secara lingual masyarakat Tondano, ungkapan tersebut dapat diterjemahkan sebagai berikut:

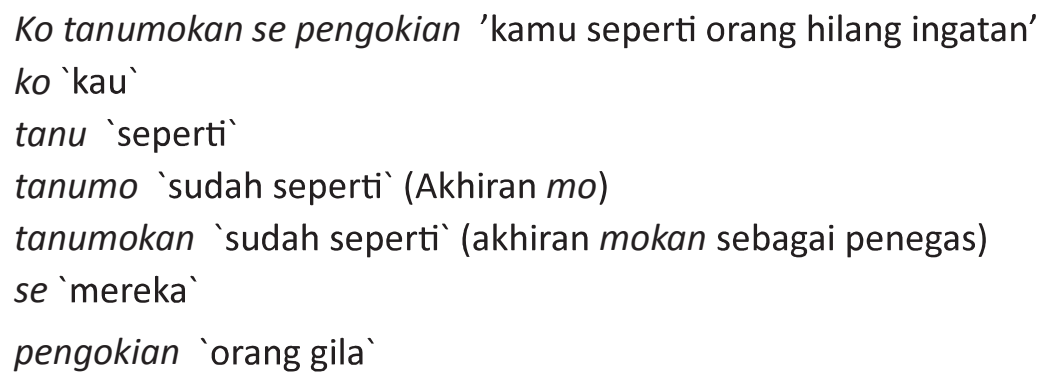

Ungkapan Pinekasaan wiles/towo ' orang yang penuh dengan dusta' memberikan gambaran atau makna orang yang hidupnya penuh dengan dusta dan selalu merugikan orang lain. Pola pikir yang terbentuk pada masayarakat Tondanao bahwa orang yang seperti itu tidak dapat dipercaya apalagi dijadikan teman.

Secara lingual masyarakat Tondano, ungkapan tersebut dapat diterjemahkan sebagai berikut:

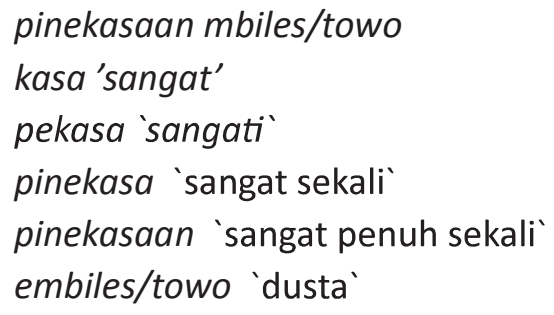

Ungkapan Saru lutu tamburi mata 'depan masak, belakang mentah' merupakan ungkapan orang Tondano yang ditujukan pada orang yang cari gampang. Pola pikir yang terbentuk adalah sifat cari gampang adalah tindakan yang memalukan karena dianggap malas dan tidak punya usaha atau semangat bekerja. Orang Tondano mempunyai moto bahwa untuk mendapatkan sesuatu seseorang harus bekerja keras.

Secara lingual masyarakat Tondano, ungkapan tersebut dapat diterjemahkan sebagai 
berikut:

Saru lutu tamburi mata 'menghadap masak membelakangi mentah'

saru 'hadap'

lutu 'masak'

tamburi 'membelakang'

mata 'mentah`

Ungkapan kete kokong 'keras kepala' adalah orang yang tidak dapat diatur dan selalu mengikuti kemauan sendiri. Pola pikir yang terbentuk dalam masayarakat Tondano adalah keras kepala merupakan sifat yang tidak baik.

Secara lingual masyarakat Tondano, ungkapan tersebut dapat diterjemahkan sebagai berikut:

kete kokong

kete 'keras'

kokong 'kepala’

Ungkapan penikoan 'tempat yang banyak ikannya' untuk masyarakat Tondano ungkapan ini mengandung makna tempat basah atau posisi yang banyak menghasilkan uang. Pola pikir yang terbentuk pada masyarakat Tondano bahwa ada jabatan dalam pemerintahan yang banyak mendatangkan uang dan ada jabatan yang kurang mendatangkan uang.

Secara lingual masyarakat Tondano, ungkapan tersebut dapat diterjemahkan sebagai berikut :

Penikoan 'tempat basah atau posisi yang banyak menghasilkan uang'

siko 'memakan umpan'

penikoan 'tempat yang banyak ikan'

Ungkapan tinumpaano ne ngaangak 'suda ditangani pejabat pusat' sindiran mengungkapkan bahwa pimpinan pusat selalu melakukan segala sesuatu menurut aturan mereka. Pola pikir yang terbentuk pada masyarakat Tondano bahwa perkara atau persoalan yang ditangani oleh pimpinan pusat pasti terselesaikan apapun masalahnya.

Secara lingual masyarakat Tondano, ungkapan tersebut dapat diterjemahkan sebagai berikut:

tinumpaano ne ngaangak

tumpa 'turun`

tinumpaan 'turun tangan'

no '...'

ne 'mereka'

ngaangak 'burung besar’

Ungkapan Tanumokan lodei lingkat `berjalan seperti perahu oleng` bermakna bahwa cara orang yang mabuk berjalan seperti orang pincang. Pola pikir yang terbentuk pada masyarakat Tondano bahwa orang mabuk jalannya oleng dan tidak seimbang.

64 | Ranah, Volume 2, Nomor 1, Juli 2013 
Secara lingual masyarakat Tondano, ungkapan tersebut dapat diterjemahkan sebagai berikut:

Ko tanumokan lodei lingkat

tanu 'seperti'

tanumo 'sudah seperti

tanumokan 'sudah seperti'

lodei 'perahu'

lingkat 'oleng’

Ungkapan tanumokan limeek wia nango perah 'seperti orang yang bersandar pada jerami' makna sosial yang ada dalam ungkapan ini adalah seperi orang yang berpijak pada dasar yang tidak kuat sehingga mendatangkan kehancuran atau celaka. Pola pikir yang terbentuk pada masayrakat Tondano bahwa dasar pijakan harus kuat untuk menopang beban yang besar.

Secara lingual masyarakat Tondano, ungkapan tersebut dapat diterjemahkan sebagai berikut:

Tanumokan limeek wia nango perah

Tanu 'seperti”

Tanumo 'sudah seperti

Tanumokan 'sudah seperti'

Leek 'injak'

limeek 'menginjak'

wia 'di'

nango 'potongan ranting, daun, dan kayu'

perah 'kering'

Ungkapan tinongko poot/ Kenaedoante poot merupakan sindiran pada orang yang hanya memikirkan makan dan makan untuk dirinya sendiri. Sedangkan pola pikir yang terbentuk pada masyarakat Tondano adalah orang yang hanya mementingkan perut adalah orang egois dan hanya memikirkan atau mementingkan diri sendiri. Sikap seperti ini tidak disenangi orang Tondano karena mementingkan diri sendiri yang berarti tidak memikirkan orang lain.

Secara lingual masyarakat Tondano, ungkapan tersebut dapat diterjemahkan sebagai berikut:

tinongko poot 'hanya memikirkan perut'

tongko 'patuk'

tinongko 'dipatuk

kenaedoante poot 'hanya memikirkan perut'

edo 'ambil'

kaedo 'terambil'

kaedoan 'yang terambil'

kinaedoan 'hanya terdiri'

kinaedoante 'hanya terdiri dari'

poot 'perut' 
Ungkapan esa lalan esa toroan 'satu jalan satu tujuan' memiliki makna budaya yang dalam bagi orang Tondano kalimat ini merupakan ungkapan penyemangat untuk mencapai tujuan bersama. Pola pikir yang terbentuk yaitu dari ungkapan ini adalah oranag yang bersatu jalan lebih kuat daripada terpisah-pisah.

Secara lingual masyarakat Tondano, ungkapan tersebut dapat diterjemahkan sebagai berikut:

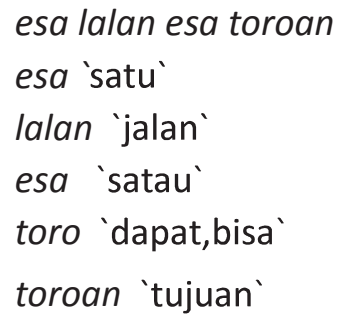

Ungkapan timekel linebetano ni edo'tidur dilewati matahari' memiliki makna bahwa orang yang tidur sampai matahari condong ke barat adalah orang yang malas. Pola pikir yang terbentuk dari ungkapan ini adalah orang malas akan dijauhi rejeki.

Secara lingual masyarakat Tondano, ungkapan tersebut dapat diterjemahkan sebagai berikut:

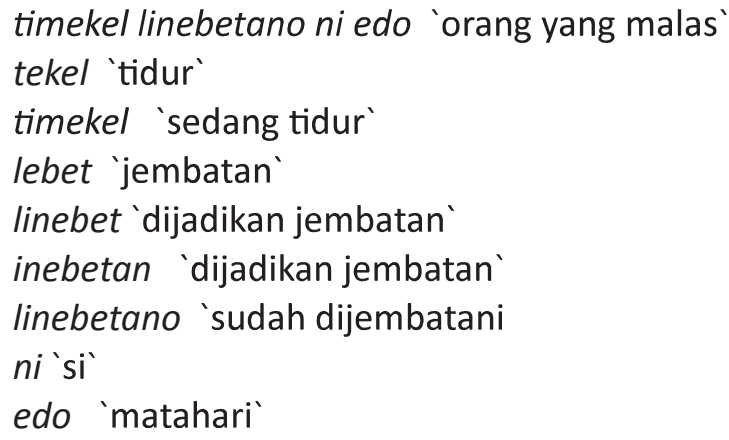

Ungkapan tanumokan winokooan kawok wuruk 'seperti orang yang dicekoki tikus mati' bermaksud untuk menyindir orang yang sudah kehilangan nyali sehingga tidak mampu berkata-kata lagi. Biasanya kehilangan nyali yang dimaksudkan dalam ungkapan ini adalah orang yang terbukti berbuat salah atau berbohong. Namun, ungkapan ini juga dapat dipakai pada orang yang sangat ketakutan terhadap sesuatu. Pola pikir yang terbentuk adalah nyali yang kadangkala mendatangkan kebaikan ataupun keburukan.

Secara lingual masyarakat Tondano, ungkapan tersebut dapat diterjemahkan sebagai berikut:

tanumokan winokooan kawok wuruk 'tidak berkata-kata lagi'

tanu 'seperti'

tanumo 'sudah seperti'

tanumokan 'sudah seperti'

woko 'suap'

winoko 'disuap'

winokoan 'disuapi'

66 | Ranah, Volume 2, Nomor 1, Juli 2013 
kawok 'tikus'

wuruk 'busuk'

\section{Simpulan dan Saran}

Dari hasil penelitian yang telah dilakukan maka dapat disimpulkan bahwa makna yang terkandung dalam ungkapan budaya pada bahasa Tondano pada umumnya sebagai nasihat dan sindiran untuk memperingatkan bahwa semua ada aturan. Pola pikir masyarakat Tondano masih terikat dengan aturan-aturan budaya yang sudah berlangsung lama.

Penelitian ini perlu dilakukan lebih lanjut mengingat masih banyak ungkapan yang ada di masyarakat Tondano yang belum diangkat untuk dilestarikan. Pola pikir dan perilaku budaya masyarakat Tondano mulai terkikis oleh perubahan global. 


\section{Daftar Pustaka}

Ahimsa-Putra, H. 2002. Tanda, Simbol, Budaya dan Ilmu Budaya. Retrieved from http://scholar.google.com

Keesing, R. M. 1992. Culture Antropology A Contemporary Perspective (Dialihbahasakan oleh Drs. Gunawan, S.M.A.) Erlangga, Jakarta

Sapir, E. 1957. "Culture Language and Personality." Dalam David G. Mandel Bounded, Selected Writings of Edward, University California Press Berkley.

Spradley. J. 1969. The Etnolographic Interview. New York: Holt Reinhart and Winston.

-------1972. Culture and Cognition: Rule, Maps, And Plans. Company, San Fransisco: Chandler

Masinambouw, E.K.M. 1988. Hubungan Timbal Balik antara Bahasa dan Kebudayaan. Ceramah. Denpasar.

Casson, R.W. 1981. Language Culture and Cognition. Anthropology Perspective. Macimillan Publishing Co, New York.

Crystal, D. 1992. The Cambridge Encyclopedia of Language. New York: Harcourt Brace Jovanovich College.

Tular D.H. 1993. “Opoisme Teologi Orang Minahasa." Tomohon: Lembaga Telaah Agama dan Kebudayaan (seminar). Minahasa.

Taulu, H.1952. Sejarah Minahasa Mimeograph. Manado: Mimeograph.

Ingkiriwang-Kalangi, 1985. "Upacara tradisional Berkaitan Dengan Peristiwa Alam dan Kepercayaan Daerah Sulawesi Utara," Jakarta

\section{Sumber Lisan}

Wawancara dengan A. A. F. Walangarei (75), Tondano, Maret 2008.

Wawancara dengan Lin Maramis (72), Tondano, Maret 2008.

Wawancara dengan Ester Politon (70), Tondano, Maret 2008.

Wawancara dengan Rommy Politon (29), Tondano, Maret 2008.

Wawancara dengan Kristiara Luntungan (22), Tondano, Maret 2008.

68 | Ranah, Volume 2, Nomor 1, Juli 2013 